\title{
Effectiveness of photodynamic therapy associated with irrigants over two biofilm models
} \author{
Marcus Vinícius Reis Só ${ }^{\mathrm{a}}$ \\ a Department of Conservative Dentistry, Federal University of Rio Grande do Sul, Porto Alegre, RS, Brazil \\ b Department of Endodontics, Centro Universitario Franciscano, Santa Maria, RS, Brazil \\ ${ }^{c}$ Department of Endodontics, Pontifícia Universidade Católica do Rio Grande do Sul, Porto Alegre, RS, Brazil \\ d Department of Oral Pathology, Federal University of Rio Grande do Sul, Porto Alegre, RS, Brazil \\ e Department of Prosthodontics, University of Southern Santa Catarina, Tubarão, SC, Brazil \\ ${ }^{\mathrm{f}}$ Department of Endodontics, São Paulo State University, Bauru, SP, Brazil
}

Ricardo Abreu da Rosa ${ }^{\mathrm{a}, *}$, Manuela Favarin Santini ${ }^{\mathrm{b}}$, José Antônio Poli de Figueiredo ${ }^{\mathrm{c}}$, Fernanda Visioli ${ }^{\mathrm{d}}$, Jefferson Ricardo Pereira ${ }^{\mathrm{e}}$, Rodrigo Ricci $\operatorname{Vivan}^{\mathrm{f}}$, Francisco Montagner ${ }^{\mathrm{a}}$,

\section{A R T I C L E I N F O}

\section{Keywords:}

Photodynamic therapy

Enterococcus faecalis

Root canal irrigants

Biofilm

Confocal laser scanning microscopy

\begin{abstract}
A B S T R A C T
Background: This study aimed to evaluate the antibacterial effect and the biofilm disruption promoted by antimicrobial photodynamic therapy (aPDT) associated with sodium hypochlorite ( $\mathrm{NaOCl}$ ) and chlorexidine (CHX) over monospecies and multispecies biofilms.

Methods: In monospecies model, forty-six premolars were inoculated with Enterococcus faecalis for 21 days and divided into three groups: saline, $\mathrm{CHX}$ and $\mathrm{NaOCl}$. After irrigation, aPDT was performed. Samples were collected at baseline (S1) and after irrigation (S2) and aPDT (S3). Colony-forming unit (CFU) counts were performed. In multispecies model, sixty bovine dentin blocks were infected intraorally for $72 \mathrm{~h}$ and divided into six groups: saline, saline/aPDT, CHX, CHX/aPDT, $\mathrm{NaOCl}$ and $\mathrm{NaOCl} / \mathrm{aPDT}$. The percentage and the biovolume of live cells and the total biovolume were assessed using confocal laser scanning microscopy.

Results: $\mathrm{CHX}$ and $\mathrm{NaOCl}$ showed the lowest $\mathrm{CFU}$ counts $(\mathrm{P}<0.05)$. aPDT reduced the bacterial counts in saline (S2-S3; P < 0.05). The lowest amount of live cells was observed in CHX, CHX/aPDT, NaOCl and NaOCl/aPDT. aPDT did not reduce the total biovolume $(\mathrm{P}>0.05)$.

Conclusion: aPDT associated with saline reduced the bacterial load in root canals infected with E. faecalis. aPDT did not reduce the total biovolume in situ; however, the irrigant was decisive to disrupt multispecies biofilms.
\end{abstract}

\section{Introduction}

Microorganisms and their products are the main responsible agents for apical periodontitis [1]. A dynamical bacterial organization adhered to a surface and embedded in an extracellular polymeric matrix, which fills the space between microorganisms, is called biofilm [2]. Endodontic biofilms are capable of resisting alkaline stress and the action of antibacterial agents, especially in cases of mature biofilms [3].

Because the morphological features of the root canal systems, the use of irrigants with antibacterial proprieties is essential to dissolve the necrotic tissue and to reduce the number of viable microorganisms [4]. Although several irrigants have been proposed, sodium hypochlorite $(\mathrm{NaOCl})$ have presented high effectiveness in eliminating endodontic pathogens, mainly due to its proteolytic action and its ability to dissolve organic tissue $[5,6]$. Chlorexidine (CHX) consists of an alternative irrigant for $\mathrm{NaOCl}$. Clinically, it presents some advantages over $\mathrm{NaOCl}$ such as: low toxicity, wide antimicrobial spectrum and substantivity [7]. The main drawback of CHX consists of its incapability to dissolve organic tissue, which impairs its clean ability [7].

Endodontic biofilms can resist the action of antibacterial irrigants using three mechanisms: failure of irrigant penetration into the biofilm, especially in deep portions; bacterial cells that present slow growing due to nutritional limitations; and adoption of phenotypes resistant to antimicrobial agents [8]. Thus, new methods have been proposed to enhance the disinfection process of the root canal system. Antibacterial photodynamic therapy (aPDT) is based on inactivation of cells, microorganisms and molecules induced by light [9]. aPDT acts through a non-toxic photoactivated dye (photosensitizer) which reacts with molecular oxygen [10]. Then, a cascade of oxidative events is produced that kill microorganisms by causing irreversible damage to essential

\footnotetext{
* Corresponding author.

E-mail address: rabreudarosa@yahoo.com.br (R.A.d. Rosa).
} 
bacterial molecules such as proteins, lipid membranes and nucleic acids [11], thus leading to microorganism death [11]. A recent systematic review has stated that the available studies indicate the influence of aPDT in reducing the microbial load within the root canal system [12].

Previous in vitro studies have evaluated the effectiveness of aPDT in reducing the microbial load in canals previously infected with monospecie biofilms, mainly with Enterococcus faecalis [13,14] and presented promising results. However, the majority of the investigations assessed the isolated use of aPDT without the influence of an irrigant with antibacterial properties. Additionally, the effect of aPDT over multispecies biofilm is not well established. Shrestha et al. [15] have evaluated the effect of antibacterial nanoparticles and aPDT over multispecies biofilm, and found cell disruption after aPDT using atomic force microscopy. Therefore, new information must be provided regarding bacterial killing and biofilm dissolution promoted by aPDT associated with irrigants both in monospecie and in multispecies biofilms.

Thus, the aim of this study was to evaluate the antibacterial effect and the biofilm dissolution promoted by aPDT associated with $2.5 \%$ $\mathrm{NaOCl}$ and 2\% CHX over monospecie (E. faecalis) and multispecies (in situ induction) biofilms. The null hypotheses were: (1) there is no difference in CFU counts after the contact with irrigants and after aPDT over monospecie biofilm; (2) aPDT does not alter neither the number of viable bacterial cells, nor the volume of multispecies biofilm assessed with confocal laser scanning microscopy (CLSM).

\section{Materials and methods}

In order to evaluate the antibacterial effects and biofilm dissolution promoted by aPDT associated with $2.5 \% \mathrm{NaOCl}$ and $2 \% \mathrm{CHX}$, in this study, it was used two methods of biofilm induction and two methods of assessment. First, a monospecie biofilm model was induced, and root canals were infected with E. faecalis (ATCC 29212). The other method induced a multispecies biofilm intraorally. The obtained data were assessed using colony-forming units (CFU) for monospecie biofilms and using CLSM for multispecies biofilms. This study was approved by the Ethics Committee of the Federal University of Rio Grande do Sul (09157313.4.0000.5347).

\subsection{Monospecie biofilm model (ATCC 29212)}

Forty-six premolars were selected, cleaned, sterilized in autoclave (30 min, $121{ }^{\circ} \mathrm{C}$, and $1 \mathrm{~atm}$ ), and stored in saline at $4{ }^{\circ} \mathrm{C}$. Periapical radiographs were performed to confirm the presence of one root canal, absence of calcification, root resorption, complete root formation, and absence of endodontic treatment. All crowns were removed and the working length was established as being $1 \mathrm{~mm}$ lower than the apical foramen. To standardize the canal diameter, canals were prepared with an F2 instrument (ProTaper Universal ${ }^{\circ}$, Dentsply Maillefer, Ballaigues, Switzerland) under constant irrigation/aspiration with $2.5 \% \mathrm{NaOCl}$ (Farmácia Marcela, Porto Alegre, RS, Brazil). Next, canals were rinsed with 17\% ethylenediaminetetraacetic acid (EDTA) (Biodinâmica, Ibiporã, PR, Brazil) and manually agitated for three minutes to remove smear layer. After, they were rinsed with saline.

The apices were sealed with adhesive system (Single Bond, $3 \mathrm{M}$ ESPE, USA) and composite resin (Magicfill Vigodent-Coltene, São Paulo, SP, Brazil), and the outer surface of the root was waterproofed with nail varnish. The next step was to fix the roots in 12-well cell culture plates and to perform the sterilization with ethylene oxide. The effectiveness of sterilization was confirmed by collecting one sample using three size 25 paper points (Tanariman, Manacapuru, AM, Brazil). Paper points were placed in polyethylene tubes (Eppendorf do Brasil Ltda, São Paulo, SP, Brazil) with $1 \mathrm{~mL}$ of Brain Heart Infusion (BHI) (BHI; Difco, Detroit, MI, EUA) and stored at $37^{\circ} \mathrm{C}$ for 7 days. Medium turbidity was assessed every $24 \mathrm{~h}$. After seven days, no turbidity was verified, which indicated the effectiveness of the sterilization process.

E. faecalis strains (ATCC 29212) were used to infect the specimens.
A suspension was prepared with $1 \mathrm{~mL}$ of pure culture of E. faecalis seeded in BHI agar plates and incubated for $24 \mathrm{~h}$ at $37^{\circ} \mathrm{C}$. The cell suspension was adjusted through spectrophotometry to match the turbidity of a McFarland 0.5 scale $\left(1.5 \times 10^{8} \mathrm{CFU} \mathrm{mL}^{-1}\right)$. Fifty microliters of bacterial broth were inoculated into the root canals and all the roots were maintained for 21 days at $37^{\circ} \mathrm{C}$ [16]. Every other day, $25 \mu \mathrm{L}$ of this mixture was removed from each canal and $25 \mu \mathrm{L}$ of pure BHI broth was inserted to guarantee cell nutrition and viability. A sterile cotton pellet was soaked BHI and placed at the root canal opening.

After incubation, the samples were randomly divided into three groups according to the following irrigants $(\mathrm{N}=15)$ : saline, $2.5 \%$ $\mathrm{NaOCl}$, and 2\% CHX (Farmácia Marcela, Porto Alegre, RS, Brazil). Sample collection and CFU counts were performed at three moments: before irrigation (S1), immediately after irrigation (S2), and after aPDT (S3). Each sample collection was obtained using three sterile paper points, which were inserted into the canals for $1 \mathrm{~min}$ and then transferred to tubes with $1 \mathrm{~mL}$ of sterile saline. Decimal serial dilutions were made and aliquots were seeded in triplicate onto Petri dishes containing tryptic soy agar (TSA; Difco) and incubated in microaerophillic conditions at $37^{\circ} \mathrm{C}$ for $24 \mathrm{~h}$. Bacterial growth was measured by the $\mathrm{CFU} / \mathrm{mL}$ counts of E. faecalis. Monoinfection with $E$. faecalis was confirmed by Gram staining and catalase testing.

Afterward, irrigation protocols were performed as follows: irrigation with $5 \mathrm{~mL}$ of the tested solution for $5 \mathrm{~min}$ using a plastic syringe and a 30G NaviTip ${ }^{\circledR}$ needle (Ultradent Products, Inc., South Jordan, UT, USA). Once the irrigation process was accomplished, the canals were dried with aspiration tips (Endo Tips, Angelus, Londrina, PR, Brazil) and paper points. Then, a second sample (S2) was performed, and serial dilutions were performed as described before.

Immediately after S2, the canals were filled with $50 \mu \mathrm{L}$ of $0.01 \%$ methylene blue (Chimiolux 10; DMC, São Carlos, SP, Brazil). The photosensitizer was maintained within the canal and manually agitated using a K-file size 20 for $1 \mathrm{~min}$ (pre-irradiation time). Next, Therapy XT diode laser (DMC, São Carlos, SP, Brazil), with $100 \pm 20 \% \mathrm{~mW}$ and red continuous emission ( $650 \pm 10 \mathrm{~nm}$ wavelength), with an intracanal fiber attached, was used. The root canals were irradiated for $60 \mathrm{~s}$ with an intracanal optical fiber $(0.6 \mathrm{~mm}$ diameter) placed $2 \mathrm{~mm}$ short of the working length as recommended by the manufacturer. After aPDT, canals were flushed with $1 \mathrm{~mL}$ of saline, and sample collection was performed (S3). One blinded evaluator performed the CFU counts $24 \mathrm{~h}$ after each sample.

\subsection{Multispecies biofilm model}

Sixty bovine dentin blocks $(3 \times 3 \mathrm{~mm})$ were obtained from sterilized bovine roots. The samples were treated with $3 \mathrm{~mL}$ of $1 \% \mathrm{NaOCl}$ for $15 \mathrm{~min}$ (the irrigant was renewed every $5 \mathrm{~min}$ ) and further treated with $3 \mathrm{~mL}$ of $17 \%$ EDTA for $5 \mathrm{~min}$ to eliminate the smear layer produced during the sectioning process. Dentin blocks were stored in plastic tubes containing $5 \mathrm{~mL}$ of distilled water and sterilized by autoclaving for $30 \mathrm{~min}$ at $121^{\circ} \mathrm{C}$, and $1 \mathrm{~atm}$.

Prior to the in situ induction of oral biofilm, a Hawleys orthodontic device was performed on two volunteers (MFS and RAR). Then, dentin samples were fixed with sticky wax (DFL Indústria e Comércio, Jacarepaguá, RJ, Brazil) on the orthodontic device so that they were exposed to the oral environment $1 \mathrm{~mm}$ above the surface to allow the biofilm formation. The volunteers used the device for $72 \mathrm{~h}$, except during regular hygiene procedures in order to induce a multispecies biofilm [4]. Regular daily food diet and hygiene procedures were maintained. In order to protect the samples, a grille was fixed on the device to prevent mechanical removal of the biofilm.

After intraoral biofilm formation, each sample was removed and stored in plastic tubes containing $1 \mathrm{~mL}$ of BHI broth at $37^{\circ} \mathrm{C}$ for $24 \mathrm{~h}$ in aerobic conditions. This procedure was performed to promote the growing of the biofilm. Next, the dentin blocks were rinsed with $1 \mathrm{~mL}$ of distilled water to remove the culture medium and those cells that did 
not adhere to the dentin surface.

Specimens were randomly divided into six groups $(\mathrm{N}=10)$ : Saline, Saline/aPDT, NaOCl, NaOCl/aPDT, CHX, and CHX/aPDT. Each sample was immersed individually in $5 \mathrm{~mL}$ of the irrigant in a 12-well culture plate for $5 \mathrm{~min}$. Specimens which were photoactivated were immersed in $5 \mathrm{~mL}$ of $0.01 \%$ of blue methylene (Chimiolux 10; DMC) for $1 \mathrm{~min}$ (pre-irradiation time). Next, photoactivation was performed using a diode laser unit (Therapy XT; DMC) as described in monospecie biofilm. However, in multispecies biofilm, the optical fiber was not used. After immersion in methylene blue in groups without aPDT and after aPDT in other groups, dentin surfaces were rinsed with $1 \mathrm{~mL}$ of saline.

The analysis of biofilm viability was performed by using the SYTO 9 and propidium iodide technique (Live/Dead, BacLight Bacterial Viability, Invitrogen, Eugene, OR). SYTO 9 is a green-fluorescent stain that labels both live and dead microorganisms, whereas propidium iodide is a red-fluorescent nucleic acid stain that just labels cells with damaged membranes (dead microrganisms). First of all, $10 \mu \mathrm{L}$ of each stain were mixed in a sterilized plastic tube. Then, a $4 \mu \mathrm{L}$ aliquot was placed on the dentin surface. A confocal laser scanning microscope was used to assess the images (Olympus Fluoview 1000, Olympus Corporation, Tokyo, Japan). The respective absorption and emission wavelengths were $494 / 518 \mathrm{~nm}$ for SYTO 9 and 536/617 nm for propidium iodide. Three confocal 'stacks' from random areas were obtained from each sample using a $100 \times$ oil lens $(1 \mu \mathrm{m}$ step size $)$ and a format of $512 \times 512$ pixels. Finally, thirty stacks were obtained in each experimental group (three images per specimen $\times$ ten samples per group). Biofilm quantitative analysis was assessed using bioImage_L software (www.bioImageL.com). The outcomes evaluated were total biovolume $\left(\mu \mathrm{m}^{3}\right)$, biovolume of live cells $\left(\mu \mathrm{m}^{3}\right)$, and the percentage of live cells.

\subsection{Statistical analysis}

The data found in monospecie and multispecies biofilm models were assessed using SPSS software version 16.0 for Windows (SPSS Co., Chicago, IL, USA). Normality assumptions could not be verified (Shapiro-Wilk test, $\mathrm{p}<0.05$ ), thus non-parametric tests were performed.

In monospecie biofilm model, inter-group analysis was performed using Kruskal-Wallis and Dunn post hoc tests in order to compare CFU counts in each experimental time. Intra-group analysis was conducted using Friedman's test in order to compare each group in different experimental times. For multispecies biofilm model, Kruskal-Wallis and Dunn post hoc tests were used to compare the total biovolume, biovolume of live cells $\left(\mu \mathrm{m}^{3}\right)$, and the percentage of live cells. The level of significance was set at $5 \%$ for all the statistical tests.

\section{Results}

\subsection{Monospecie biofilm model}

CFU counts were similar in $\mathrm{S} 1$ ( $\mathrm{P}>0.05)$. A reduction of $\mathrm{CFU}$ counts in all groups was observed, including Saline, after canal irrigation (S2) $(\mathrm{P}<0.05)$. However, the main reduction of CFU counts occurred in $\mathrm{CHX}$ and $\mathrm{NaOCl}$ groups, with no differences between them $(\mathrm{P}<0.05)$. aPDT presented a significant role in the reduction of CFU counts in Saline group (Saline S2-S3; P $<0.05$ ). On the other hand, aPDT reduced the $\mathrm{CFU}$ counts in $\mathrm{NaOCl}$ and $\mathrm{CHX}$ groups (S2-S3); however, Kruskal-Wallis test did not point significant differences (S2-S3; P > 0.05). After aPDT (S3), the lowest CFU counts were observed in $\mathrm{NaOCl}(0)$ and $\mathrm{CHX}\left(0.0041 \times 10^{4} \mathrm{CFU} / \mathrm{mL}\right)$ groups, with no differences between them $(\mathrm{P}>0.05)$. Table 1 shows the median, 25th and 75th percentiles of CFU counts $\left(\times 10^{4} \mathrm{CFU} / \mathrm{mL}\right)$ in all experimental times and the reduction of bacterial load (\%) in S1-S2 and in S2-S3.
Table 1

Median, 25th and 75th percentiles of CFU counts $\left(\times 10^{4} \mathrm{CFU} / \mathrm{mL}\right)$ at baseline (S1), after irrigation (S2) and after aPDT (S3), and the reduction of bacterial load (\%) after each experimental time in monospecie biofilm model.

\begin{tabular}{|c|c|c|c|c|c|}
\hline & S1 & S2 & S3 & S1-S2 (\%) & S2-S3 (\%) \\
\hline Saline & $\begin{array}{l}200^{\mathrm{Aa}} \\
(160-780)\end{array}$ & $\begin{array}{l}11.6^{\mathrm{Ba}} \\
(6.6-21.5)\end{array}$ & $\begin{array}{l}3.4^{\mathrm{Ca}} \\
(0.9-7)\end{array}$ & $94.1 \%$ & $70.6 \%$ \\
\hline $\mathrm{NaOCl}$ & $\begin{array}{l}100.7^{\mathrm{Aa}} \\
(37.7-200)\end{array}$ & $\begin{array}{l}0.6^{\mathrm{Bb}} \\
(0-11.2)\end{array}$ & $\begin{array}{l}0^{\mathrm{Bb}} \\
(0-7.1)\end{array}$ & $99.4 \%$ & $100 \%$ \\
\hline CHX & $\begin{array}{l}108.2^{\mathrm{Aa}} \\
(30.8-239.7)\end{array}$ & $\begin{array}{l}1.6^{\mathrm{Bb}} \\
(0.4-3.6)\end{array}$ & $\begin{array}{l}0.0041^{\text {вь }} \\
(0-1.5)\end{array}$ & $98.3 \%$ & $99.3 \%$ \\
\hline
\end{tabular}

Footnotes: Different uppercase letters in the row denote significant differences after Friedman test $(\mathrm{P}<0.05)$. Different lowercase letters in the column denote significant differences after Kruskal-Wallis and Dunn post hoc tests $(\mathrm{P}<0.05)$.

\subsection{Multispecies biofilm model}

Median and 25th and 75th percentiles of total biovolume, biovolume of live cells, and the percentage of live cells after chemical action and aPDT procedures are presented in Table 2. Regardless the application of aPDT, $\mathrm{NaOCl}$ and $\mathrm{CHX}$ showed the lowest amount of live cells in comparison with Saline $(\mathrm{P}<0.05)$, but with no differences between them $(\mathrm{P}>0.05)$. Application of aPDT after saline (Saline/PDT) did not reduce the percentage of live cells (green) $(\mathrm{P}>0.05)$. On the other hand, despite absence of significant differences, it can be noted that the percentage of live cells in $\mathrm{NaOCl} / \mathrm{aPDT}$ (24.3\%) decreased $62 \%$ in comparison with $\mathrm{NaOCl}(64.4 \%)$. Similar results were found in CHX/ aPDT (29.9\%). There was a reduction of $35 \%$ of live cells in comparison with CHX (46\%).

aPDT was not able to reduce the total biovolume of biofilm ( $P>0.05)$; however, the type of the irrigant was determinant to disrupt biofilm $(\mathrm{P}<0.05)$. $\mathrm{NaOCl}$ and $\mathrm{NaOCl} / \mathrm{aPDT}$ presented lower total biovolume values in comparison with Saline and Saline/aPDT $(\mathrm{P}<0.05)$. CHX and CHX/aPDT showed intermediary biovolume of biofilm. Representative CLSM images are shown in Fig. 1.

aPDT reduced the biovolume of live cells; however, statistical differences were not observed $(\mathrm{P}>0.05)$. The lowest biovolume of live cells was observed in $\mathrm{NaOCl} / \mathrm{aPDT}\left(0.4 \times 10^{6} \mu \mathrm{m}^{3}\right)(\mathrm{P}<0.05)$. On the other hand, Saline and Saline/aPDT presented the highest biovolume of live cells $\left(64.8 \times 10^{6} \mu \mathrm{m}^{3}\right.$ and $40.5 \times 10^{6} \mu \mathrm{m}^{3}$, respectively) $(\mathrm{P}<0.05)$.

\section{Discussion}

Root canal disinfection is a challenge and sometimes other therapeutic modalities must be addressed to improve the reduction of bacterial loads. In this sense, aPDT has been proposed as an auxiliary method to treat the infection of the root canal system $[10,12,17,18]$. Because of methodological reasons, this study was designed to evaluate the antibacterial effect and the capability of biofilm dissolution of three irrigants and their association with aPDT over monospecie and multispecies biofilms. It must be highlighted that the irrigation is just one step of the endodontic treatment. Disinfection procedures are still composed of the mechanical action of the endodontic instruments and further placement of root canal dressings.

Previous studies have assessed the isolated effect of aPDT in root canal disinfection; however, they did not evaluate the effect of aPDT associated with endodontic irrigants with antibacterial properties such as $\mathrm{NaOCl}$ and $\mathrm{CHX}[13,19]$. Recently, Ghinzelli et al. [13] compared the regular method of aPDT with ultrasonic activation of the sensitizer (i.e. methylene blue) previously to aPDT on the E. faecalis elimination from root canals infected in vitro, and found better results for the last method. aPDT must be performed after complete root canal preparation and not alone. Therefore, methodologies which investigate the combined effect of aPDT with antibacterial irrigants, endodontic instruments, and other 
Table 2

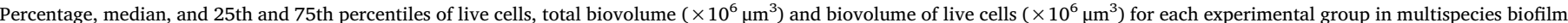
model.

\begin{tabular}{|c|c|c|c|c|c|c|}
\hline & Saline & Saline/PDT & $\mathrm{NaOCl}$ & $\mathrm{NaOCl} / \mathrm{PDT}$ & CHX & CHX/PDT \\
\hline Percentage of live cells & $93,1 \%{ }^{\mathrm{A}}(91.6-94.7)$ & $91.2 \%{ }^{\mathrm{A}}(84.7-92.8)$ & $64.4 \%{ }^{\text {в }}(40-72.7)$ & $24.3 \%{ }^{\mathrm{B}}(1.8-58.6)$ & $46.0 \%{ }^{\mathrm{B}}(41.2-60.2)$ & $29.9 \%{ }^{\text {B }}(27.9-56.1)$ \\
\hline Total biovolume & $75.5^{\mathrm{A}}(45.5-119.8)$ & $44.4^{\mathrm{A}}(36.4-94.0)$ & $9.3^{\mathrm{B}}(5.1-16.5)$ & $10.3^{\mathrm{B}}(0.6-12.5)$ & $33.9^{\mathrm{AB}}(32.4-47.1)$ & $35.1^{\mathrm{AB}}(27.3-66.7)$ \\
\hline Biovolume of live cells & $64.8^{\mathrm{A}}(42.9-113.2)$ & $40.5^{\mathrm{A}}(33.2-80.9)$ & $7.1^{\mathrm{B}}(2.7-16.5)$ & $0.4^{\mathrm{B}}(0.07-7.4)$ & $23.5^{\mathrm{AB}}(14.2-27.8)$ & $9.8^{\mathrm{B}}(6.8-39.0)$ \\
\hline
\end{tabular}

Footnote: Different uppercase letters in the row denote significant differences after Kruskal-Wallis and post-hoc Dunn tests (P < 0.05).

disinfection techniques seem adequate. Furthermore, the reduction of bacterial load promoted by the irrigants or root canal preparation must be enough to achieve healing of the periapical lesion.

The first null hypothesis was rejected. There was significant difference in CFU counts after contact with the irrigants and after aPDT in monospecie biofilm model. At the baseline (S1), CFU counts were similar in all groups $(P>0.05)$. Such result plays an important role since it can identify homogeneous infection pattern using the applied methodology. This study showed the chemical action of the irrigant and the physical effects of irrigation/aspiration process and aPDT over $E$. faecalis biofilm. If the variable root canal preparation (i.e., mechanical effect) was included in the study, probably the bacterial load observed at baseline would be too small and would minimize the chemical effect of the irrigants and aPDT, objects of this study [16]. Such aspect was observed by Dornelles-Morgental et al. [16]. These authors have performed sample collection after hand preparation up to size $50 \mathrm{~K}$-files associated with $2.5 \% \mathrm{NaOCl}$ or $2 \% \mathrm{CHX}$, among other irrigants and associations. Canals prepared and irrigated with $2.5 \% \mathrm{NaOCl}$ and $2 \%$ CHX did not present CFU immediately after canal preparation, probably because of the chemical effect of the irrigants combined with the mechanical action of the instruments.

Significant reduction in CFU counts was observed in S2 in all groups, including Saline $(\mathrm{P}<0.05)$. This finding occurred because of the physical action of the irrigation/aspiration process, which is responsible for the reduction of planktonic microrganisms (observed by collect methods and further culture). Physical action combined with the antimicrobial potential of $2.5 \% \mathrm{NaOCl}$ and $2 \%$ CHX promoted the lowest CFU counts in S2 $(\mathrm{P}<0.05)$ with no significant differences between them $(\mathrm{P}>0.05)$. The antimicrobial potential of these irrigants is well established, especially when the evaluation method is based on sample collection using paper points [16,20]. Additionally, literature widely indicates $2.5 \% \mathrm{NaOCl}$ and $2 \% \mathrm{CHX}$ to disinfect necrotic canals [21]. Rôças and Siqueira [21], in a clinical study using forty-seven teeth with chronic apical periodontitis, found similar reduction of microorganism phenotypes and their levels when canals were treated with $0.12 \% \mathrm{CHX}$ and $2.5 \% \mathrm{NaOCl}$.

Previous studies have confirmed the bactericidal effect of aPDT, mainly when associated with antibacterial irrigants [17,19]. A recent systematic review alerts to the shortage of clinical information regarding antimicrobial potential related to aPDT; however, it points to an effectiveness ranging from 91 to $100 \%$ in disinfecting the root canal system [12]. This investigation found a reduction of bacterial load of $70 \%$ in Saline after aPDT (S3) $(\mathrm{P}<0.05)$. Similar values to those were obtained by Foschi et al. [19], who observed a 77\% reduction of bacterial load after using diode laser with optical fiber and methylene blue as photosensitizer.

On the other hand, when aPDT was performed after irrigation with $\mathrm{NaOCl}$ and $\mathrm{CHX}$ (S3), the CFU counts were lower than those obtained after irrigation alone, but with no significant differences $(\mathrm{P}>0.05)$. The use of antibacterial irrigants alone was enough to reduce CFU counts so the effect of aPDT could not be statistically detected. An important finding that must be pointed is that after aPDT (S3), 50\% and $60 \%$ of the $\mathrm{NaOCl}$ and $\mathrm{CHX}$ samples, respectively, did not present CFU. This finding is accordance with the findings of Garcez et al. [17] who found a significant decrease in bacterial loads after endodontic treatment using $2.5 \% \mathrm{NaOCl}$ as irrigant. Thirty-three per cent of the samples treated with conventional endodontic treatment presented themselves free of microorganisms, while those treated with aPDT presented absence of microorganisms under the conventional culture methods.

The second null hypothesis was confirmed. aPDT did not reduce neither the amount of live cells nor the biovolume of multispecies biofilms under CLSM. In this study, antibacterial effect of aPDT when
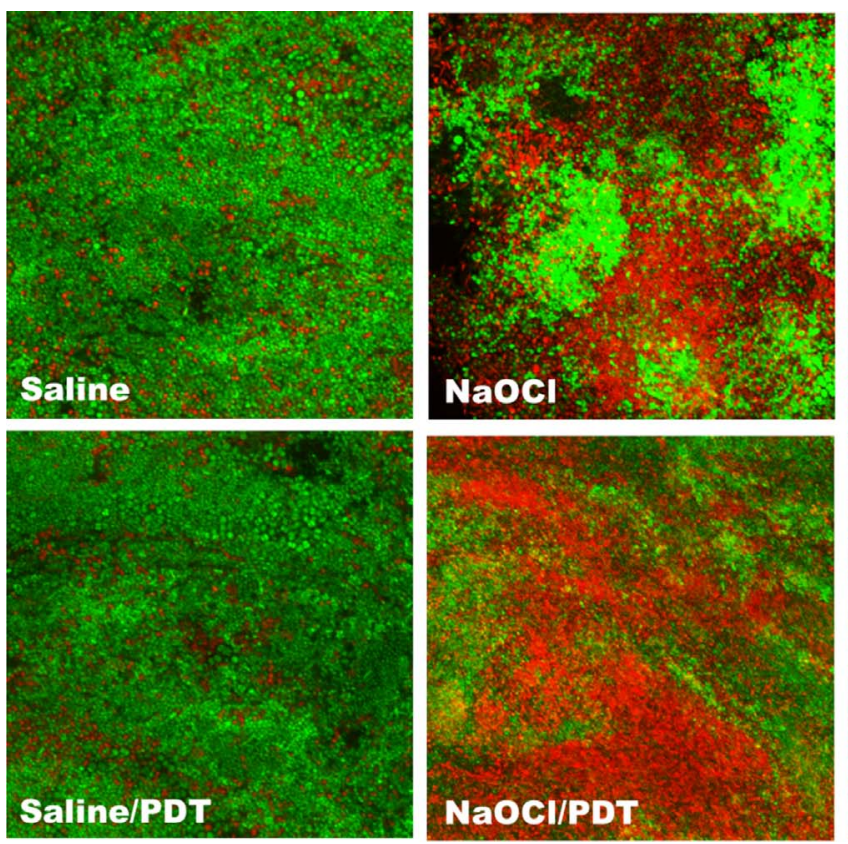

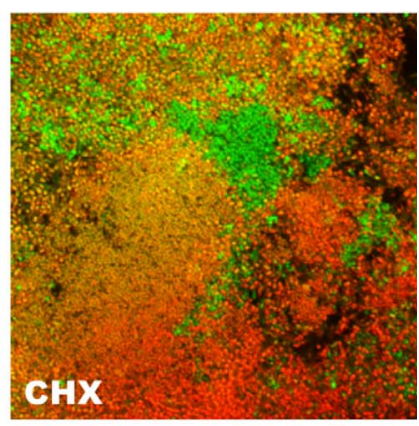

Fig. 1. CLSM images of live (green) and dead (red) cells in all experimental groups. 
specimens were submerged in saline was not observed. The amount of live cells in Saline and Saline/aPDT was similar (93.1\% and $91.2 \%$, respectively). Saline is an inert solution, devoid of any antibacterial capacity. Thus, it was expected not to find antibacterial action promoted by saline, and for this reason, it was analyzed as a control group. In previous studies, saline was proposed as being a control group to compare its findings with those obtained with $\mathrm{NaOCl}$, CHX and aPDT $[3,18]$. Methodology limitations can explain the $7 \%$ of dead cells (red) in Saline and 9\% in Saline/aPDT. This occurred probably because of the saturation of the culture medium or during specimens processing for CLSM analysis.

In those groups in which irrigants with antibacterial properties were used, aPDT seems to play a complementary antibacterial effect; however, statistical differences were not observed $(\mathrm{P}>0.05)$. In $\mathrm{NaOCl} /$ aPDT, there was a $62 \%$ reduction in the number of live cells when compared with NaOCl. On the other hand, in CHX/aPDT the reduction was $35 \%$. The reason of why aPDT has a greater antibacterial effect after irrigation with antibacterial irrigants remains unclear.

Antibacterial effect of aPDT after using $\mathrm{NaOCl}$ and $\mathrm{CHX}$ can be explained because the irradiation over the photosensitizer may be more effective when only residual microorganisms remain in the root canal system after the first contact with the irrigant. Such aspect highlights the adjuvant role of aPDT on the disinfection process [17,22]. Furthermore, when the biofilm is well structured without being partially disrupted by the irrigant or the mechanical action of the canal preparation, aPDT seems not to present effectiveness (Saline and Saline/ aPDT, P > 0.05).

Several studies have evaluated the antibacterial effect but not the capability of biofilm dissolution promoted by photoactivated disinfection $[3,10,12-15,17-19,22]$. The ability to dissolve organic tissue of the irrigants is directly related to their chemical nature and, in the case of $\mathrm{NaOCl}$, to its concentration $[5,6]$. This study is in agreement with previous reports in which the lowest volumes of biofilms were observed when specimens were irrigated with $\mathrm{NaOCl}[5,6]$. In addition, authors have been unanimous in affirming that CHX is not capable of dissolve vital or necrotic pulp tissue or biofilms [23]. This investigation found intermediary values of total biovolume in groups treated with CHX $\left(33.9 \times 10^{6} \mu^{3}\right.$ for CHX and $35.1 \times 10^{6} \mu \mathrm{m}^{3}$ for CHX/aPDT); however, it must be considered that organic matter reported in this study consisted only of multispecies biofilm, and not of other organic contents such as pulp tissue and collagen fibers. The most reasonable explanation for this finding seems to be related to bactericide effect of $2 \%$ CHX. According to Gomes et al. [23], when $2 \%$ CHX is used, the precipitation/coagulation of bacterial cytoplasm occurs. This phenomenon generates cellular debris that may be easily removed after vigorous irrigation with saline [24]. In this study, the removal of this content probably occurred during the irrigation with $1 \mathrm{~mL}$ of saline after immersion in CHX. Moreover, the bactericide effect of $2 \%$ CHX on biofilms may be decreased due to the inactivation of the cationic bisbiguanides by organic content and their limited penetration through the extracellular polymeric matrix [25].

It must be pointed out that the methodology used in this study did not include the assessment of bacterial viability into the dentin tubules in monospecie biofilm model. This aspect can be evaluated in future studies, which aimed to assess the effect of the irrigants associated with aPDT within the dentin tubules and canal irregularities, especially in teeth with anatomical complexities. Moreover, multispecies biofilm model presents as a substrate a flat surface in which the biofilm grows. Because this study aimed to assess be viability and dissolution of multispecies biofilm formed over dentine and not within the dentin tubules bovine dentin blocks were used. Then, the access of the irrigants, the photosensitizer and the red light is easy. As a result, the antibacterial effect and biofilm dissolution promoted by the irrigants and by aPDT must be overestimated. In multispecies biofilm model, it is difficult to induce biofilm formation with consistent characteristics within dentin tubules because of variation in dentinal tubule size, nutrient supply, and expression of key binding molecules [26] and for this reason the assessment of live cells was not performed. However, previous studies already reported the effect of irrigants over biofilms within dentin tubules after contamination by centrifugation [26,27]. Finally, the induction of mutlispecies biofilm model in aerobic conditions did not favor gram-negative anaerobes microorganisms which play important role in endodontic infections [28,29].

Based on the results of this study and considering its limitations, it can be concluded that aPDT, when used after previous irrigation with saline, reduced the CFU counts in canals infected with monospecie biofilm (E. faecalis). With regard to multispecies biofilm induced in situ, aPDT seems to reduce the amount and volume of live cells when associated with $\mathrm{NaOCl}$ and $\mathrm{CHX}$. aPDT did not reduce the total volume of biofilm induced in situ, but the type of irrigant was determinant to dissolve it.

\section{Acknowledgements}

This study was supported by grants from the Brazilian funding agency CAPES and from Federal University of Rio Grande do Sul.

\section{References}

[1] D. Ricucci, J. Siqueira Jr., Biofilms and apical periodontitis: study of prevalence and association with clinical and histopathologic findings, J. Endod. 36 (8) (2010) $1277-1288$.

[2] J. Costerton, The Biofilm Primer, 1st ed., Springer, Berlin/New York, 2007.

[3] V. Zand, A.S. Milani, M. Amini, M. Barhaghi, M. Lotfi, S. Rikhtegaran, et al., Antimicrobial efficacy of photodynamic therapy and sodium hypochlorite on monoculture biofilms of Enterococcus faecalis at different stages of development, Photomed. Laser Surg. 32 (5) (2014) 245-251.

[4] A.E. Del Carpio-Perochena, C.M. Bramante, M.A.H. Duarte, B.C. Cavenago, M. Villas-Boas, M. Graeff, et al., Biofilm dissolution and cleaning ability of different irrigant solutions on intraorally infected dentin, J. Endod. 37 (8) (2011) 1134-1138.

[5] L.E. Irala, R. Grazziotin-Soares, A.A. Salles, A.Z. Munari, J.S. Pereira, Dissolution of bovine pulp tissue in solutions consisting of varying $\mathrm{NaOCl}$ concentrations and combined with EDTA, Braz. Oral Res. 24 (3) (2010) 271-276.

[6] M.V.R. Só, F. Vier-Pelisser, M. Darcie, D. Smaniotto, F. Montagner, M.C. Kuga, Pulp tissue dissolution when the use of sodium hypochlorite and EDTA alone or associated, J. Dent. Sci. 26 (2) (2011) 156-160.

[7] C.C. Ferraz, B.P. Gomes, A.A. Zaia, F.B. Teixeira, F.J. Souza-Filho, Comparative study of the antimicrobial efficacy of chlorhexidine gel, chlorhexidine solution and sodium hypochlorite as endodontic irrigants, Braz. Dent. J. 18 (4) (2007) 294-298.

[8] T.F. Mah, G.A. O'Toole, Mechanisms of biofilm resistance to antimicrobial agents, Trends Microbiol. 9 (1) (2001) 34-39.

[9] H. Gursoy, C. Ozcakir-Tomruk, J. Tanalp, S. Yilmaz, Photodynamic therapy in dentistry: a literature review, Clin. Oral Investig. 17 (4) (2013) 1113-1125.

[10] L.C. Souza, P.R. Brito, J.C. Oliveira, F.R. Alves, E.J. Moreira, H.R. Sampaio-Filho, et al., Photodynamic therapy with two different photosensitizers as a supplement to instrumentation/irrigation procedures in promoting intracanal reduction of Enterococcus faecalis, J. Endod. 36 (2) (2010) 292-296.

[11] K. Konopka, T. Goslinski, Photodynamic therapy in dentistry, J. Dent. Res. 86 (8) (2007) 694-707.

[12] V. Chrepa, G.A. Kotsakis, T.C. Pagonis, K.M. Hargreaves, The effect of photodynamic therapy in root canal disinfection: a systematic review, J. Endod. 40 (7) (2014) 891-898.

[13] G.C. Ghinzelli, M.A. Souza, D. Cecchin, A.P. Farina, J.A.P. Figueiredo, Influence of ultrasonic activation on photodynamic therapy over root canal system infected with Enterococcus faecalis - an in vitro study, Photodiagn. Photodyn. Ther. 11 (4) (2014) $472-478$.

[14] I.B. Jurič, V. Plečko, I. Anić, S. Pleško, S. Jakovljević, J.P. Rocca, E. Medioni, Antimicrobial efficacy of photodynamic therapy, Nd:YAG laser and QMiX solution against Enterococcus faecalis biofilm, Photodiagn. Photodyn. Ther. 13 (3) (2016) $238-243$.

[15] A. Shrestha, A. Kishen, Antibiofilm efficacy of photosensitizer-functionalized bioactive nanoparticles on multispecies biofilm, J. Endod. 40 (10) (2014) 1604-1610.

[16] R. Dornelles-Morgental, J.M. Guerreiro-Tanomaru, N.B. Faria-Júnior, M.A.H. Duarte, M.C. Kuga, M. Tanomaru-Filho, Antibacterial efficacy of endodontic irrigating solutions and their combinations in root canals contaminated with Enterococcus faecalis, Oral Surg Oral Med Oral Pathol. 112 (3) (2011) 396-400.

[17] A.S. Garcez, S.C. Nuñez, M.R. Hamblim, H. Suzuki, M.S. Ribeiro, Photodynamic therapy associated with conventional endodontic treatment in patients with antibiotic-resistant microflora: a preliminary report, J. Endod. 36 (9) (2010) 1463-1466.

[18] I. Bago, V. Plečko, D. Gabrić Pandurić, Z. Schauperl, A. Baraba, I. Anić, Antimicrobial efficacy of a high-power diode laser, photo-activated disinfection, conventional and sonic activated irrigation during root canal treatment, Int. Endod. 
J. 46 (4) (2013) 339-347.

[19] F. Foschi, C.R. Fontana, K. Ruggiero, R. Riahi, A. Vera, A.G. Doukas, et al., Photodynamic inactivation of Enterococcus faecalis in dental root canals in vitro, Lasers Surg. Med. 39 (10) (2007) 782-787.

[20] B.P. Gomes, C.C. Ferraz, M.E. Vianna, V.B. Berber, F.B. Teixeira, F.J. Souza-Filho, In vitro antimicrobial activity of several concentrations of sodium hypochlorite and chlorhexidine gluconate in the elimination of Enterococcus faecalis, Int. Endod. J. 34 (6) (2001) 424-428.

[21] I.N. Rôças, J.F. Siqueira Jr., Comparison of the in vivo antimicrobial effectiveness of sodium hypochlorite and chlorhexidine used as root canal irrigants: a molecular microbiology study, J. Endod. 37 (2) (2011) 143-150.

[22] A.V. Susila, R. Sugumar, C.S. Chandana, C.V. Subbarao, Combined effects of photodynamic therapy and irrigants in disinfection of root canals, J. Biophoton. 9 (6) (2016) 603-609.

[23] B.P. Gomes, M.E. Vianna, A.A. Zaia, J.F. Almeida, F.J. Souza-Filho, C.C. Ferraz,
Chlorhexidine in endodontics, Braz. Dent. J. 24 (2) (2013) 89-102.

[24] M.E. Vianna, H.P. Horz, B.P. Gomes, G. Conrads, In vivo evaluation of microbial reduction after chemo-mechanical preparation of human root canals containing necrotic pulp tissue, Int. Endod. J. 39 (6) (2006) 484-492.

[25] M. Yamaguchi, Y. Noiri, M. Kuboniwa, R. Yamamoto, Y. Asahi, H. Maezono, et al., Porphyromonas gingivalis biofilms persist after chlorhexidine treatment, Eur. J. Oral Sci. 121 (3 (Pt. 1)) (2013) 162-182.

[26] J. Ma, Z. Wang, Y. Shen, M. Haapasalo, New noninvasive model to study the effectiveness of dentin disinfection by using confocal laser scanning microscopy, J. Endod. 37 (10) (2011) 1380-1385.

[27] T. Du, Z. Wang, Y. Shen, J. Ma, Y. Cao, M. Haapasalo, Effect of long-term exposure to endodontic disinfecting solutions on young and old Enterococcus faecalis biofilms in dentin canals, J. Endod. 40 (4) (2014) 509-514.

[28] J.F. Siqueira Jr., I.N. Rôças, Diversity of endodontic microbiota revisited, J. Dent. Res. 88 (11) (2009) 969-981. 